\title{
Classroom Management Scripts: a Theoretical Model Contrasting Expert and Novice Teachers' Knowledge and Awareness of Classroom Events
}

\author{
Charlotte E. Wolff, et al. [full author details at the end of the article]
}

Published online: 25June 2020

(C) The Author(s) 2020

\begin{abstract}
Dealing with the complexities of the classroom and the diversity of events in classroom situations presents a major challenge for classroom management. The knowledge a teacher has for processing this complexity depends a great deal on their level of experience, leading to differences in the way teachers perceive and interpret classroom events. This includes how they monitor events and how they maintain an ongoing awareness of classroom situations. It also impacts decisions about when and how to act in response to events. Research on classroom management has often focused on how to handle common classroom situations, but does not provide a theoretical description of how knowledge from experience affects teachers' awareness and ability to manage the classroom. This article proposes a definition for classroom management scripts by contrasting expert and novice teachers' knowledge and their decisions to act in response to classroom events. Classroom management scripts help clarify differences in teachers' recognition and representation of events by considering how expertise influences visual perception and mental interpretation. The proposed model exposes the internal cognitive processing involved in classroom management. Such insights can be useful for helping teacher educators and teachers themselves analyze and make sense of puzzling events. In turn, this may help develop training approaches to improve teachers' awareness of factors easily overlooked when considering classroom management, enhancing professional vision. This theory also underlines the centrality of facilitating and sustaining learning when grappling with the challenges of managing a classroom.
\end{abstract}

Keywords Teacher knowledge $\cdot$ Teacher expertise $\cdot$ Event processing $\cdot$ Classroom management . Teachers' professional vision

Charlotte E. Wolff, University of Iceland, School of Education, and the Open University of the Netherlands; Halszka Jarodzka, Welten Institute: Research Centre for Learning, Teaching, and Technology, Open University of the Netherlands, and The Eye-tracking group of the Humanities Laboratory, Lund University, Sweden; Henny P.A. Boshuizen, Welten Institute: Research Centre for Learning, Teaching, and Technology, Open University of the Netherlands, and Faculty of Education, University of Turku, Finland.

Electronic supplementary material The online version of this article (https://doi.org/10.1007/s10648-02009542-0) contains supplementary material, which is available to authorized users. 


\section{Introduction}

For anyone who has ever stood before a classroom full of students with the full weight and responsibility of managing and inspiring their learning, the sheer complexity of teaching is obvious. There is an inherent volatility to classroom events: the goals of teaching may be planned in advance, but the act of teaching to achieve intended goals unfolds spur-of-themoment as a series of events which can be interpreted by teachers in countless ways. Some events are anticipated by the plan, while others arise in response to the unexpected. Understanding these events, how they unfold over time and how they influence learning, can be a decisive factor in successful classroom management.

In spite of great efforts from educational researchers and teacher educators - not to mention the rigorous efforts of teachers themselves - teacher education programs are frequently criticized as falling short theoretically and practically when it comes to preparing teachers for the challenges of the twenty-first century classroom (Berry et al. 2010; McMahon et al. 2015; Tatto et al. 2016). Incomplete understanding in terms of what happens behind the scenes and within the heads of teachers is but one of many issues preventing teachers - those in training and those in development - from being fully prepared for classroom challenges and the work of teaching (Ball and Forzani 2009; Darling-Hammond 2006). The context of where learning to teach happens - in classrooms - is an additional complicating factor, as teachers are confronted with the challenges of crowded, demanding environments within which they must acquire and develop professional knowledge and skills (Doyle 1990). The ambiguity of classroom events - with their indistinct beginnings, endings, and meanings - makes it that much harder for teachers to develop knowledge and skills for managing learning.

Improving performance in the classroom relies on collecting and honing knowledge of events specific to the classroom. Through experience in classrooms, teachers blend formal, professional knowledge with personal and practical knowledge, reinforcing the skills and practices necessary for effective performance. Elements of teacher's practice-based performance include the following: assessing events, deciding whether or not action needs to be taken in response to these events, pursuing particular actions, and continual metacognitive monitoring (Eraut 2007). In essence, effectively managing classrooms relies on constant event awareness: repeated event monitoring, recognition of who and what needs attention, and knowledge about how to act and react (Doyle 2006; Wolff et al. 2016). Teachers new to the profession - novices - and those with highly attuned professional proficiency - experts - differ greatly in their knowledge of classroom events in relation to classroom management. Novices are rather easy to identify due to their limited hours of teaching experience - these are pre-service or first-year teachers. Identifying the knowledge and skills of expert teachers is less straightforward - expert teachers are defined as having a minimum of 10 years of teaching experience, possess degrees/qualifications in their subject area, are recognized as exemplary by multiple constituents (other teachers, administrators, teacher educators ...), and have a documented positive impact on student learning outcomes (Palmer et al. 2005). In this article, we explore these differences by constructing a theoretical model that contrasts underlying features of expert and novice teachers' knowledge and event awareness and describing how this influences their decisions to act in classroom situations.

Researchers have emphasized the importance of a more detailed understanding of the complex nature of teacher expertise, and methods for measuring and describing relative differences between experts and novices have proved useful in this regard (Berliner 2004; Bromme 2001; Livingston and Borko 1989; Schempp et al. 1998; Spalding et al. 2011; Tsui 
2003; Voss et al. 1986). Theorizing how expert and novice teachers perceive, interpret, and take action to achieve well-managed classrooms is underpinned by key differences in how classroom management knowledge is structured. Recognizing these differences can be of benefit to teachers as they strive to reflect upon and improve their classroom practice. Such theory can also support teacher educators as they strive to prepare teachers for the career-long process of professional learning linked to teaching experiences in the classroom. (Fig. 1)

In their analysis of critical concerns in teacher education, McMahon et al. (2015) emphasize the perennial tension between research about teaching and the actual practice of teaching, stating a need to construct forms of professional learning that support and sustain effective classroom practices. They argue that:

We cannot reduce teaching to a simple set of skills and routines in the classroom. Instead we need to see teaching as theoretically informed activities and that a strong theoretical base is the foundation of decisions about the learning needs of individual pupils and groups of pupils and the ways of creating contexts in which learners can flourish. (p. 170)

The theory presented here can be seen as an effort to bridge the gap between classroom management theory and the practices of actually managing classrooms. We propose a two-part theoretical model of teacher cognition that considers the knowledge structures through which teachers process and manage the ambiguity of classroom events. This model exposes what is often concealed - teachers' cognition as applied to typical classroom situations - by offering a detailed consideration of how teaching expertise influences perceptions, interpretations, and in-action responses to classroom situations. We begin by defining these knowledge structures, i.e., the classroom management scripts that are particular to the teaching domain, then we explain the model. The first part of the model describes classroom management scripts, delineating how this differs based on teachers' level of expertise and how decisions to act are activated differently (Fig. 2). The second part of our model depicts the influence these classroom management scripts have on teachers' visual perception, situational awareness, mode of cognition, and event representation (Fig. 3). In sum, our goal is to model and explain how teachers' classroom management knowledge is structured, show how this knowledge influences the simultaneous perception and interpretation of events, and then link this ongoing processing to differences in teachers' awareness of classroom situations.

\section{Core Concepts of the Theoretical Model}

Several interrelated concepts are central to understanding the proposed theoretical model.

- Perception of the classroom refers to the visual attention teachers apply to recognize what is important as they visually observe, detect, and trace connections between events and

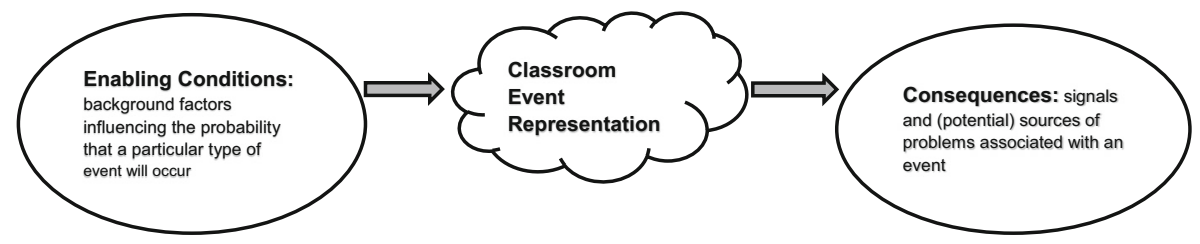

Fig. 1 The basic structure of a classroom management script, consisting of enabling conditions, the event as perceived and represented in the mind of the teacher, and consequences associated with the event 


\begin{tabular}{|c|c|c|c|c|}
\hline \multirow{2}{*}{$\begin{array}{l}\text { Novice Teachers } \\
\text { [classroom } \\
\text { management scripts } \\
\text { forming through } \\
\text { experience] }\end{array}$} & Enabling Conditions & Consequences & & Decision to Act \\
\hline & $\begin{array}{l}\text { - knowledge about: } \\
\text { - students } \\
\text { - behavioral norms }\end{array}$ & $\begin{array}{l}\text { Event: Aware v. unaware } \\
\text { Source of problem: } \\
\text { - behavioral issue of } \\
\text { student(s) }\end{array}$ & & $\begin{array}{l}\text { - ignore consequences } \\
\text { (unaware / precarious event) } \\
\text { - acknowledge and address } \\
\text { consequences } \\
\text { (aware + reactive) }\end{array}$ \\
\hline $\begin{array}{l}\text { Expert Teachers } \\
\text { [classroom } \\
\text { management scripts } \\
\text { established through } \\
\text { experience] }\end{array}$ & $\begin{array}{l}\text { - knowledge about: } \\
\text { students } \\
\text { - assessment of } \\
\text { learning } \\
\text { - classroom dynamics } \\
\text { and interactions } \\
\text { - pedagogical options } \\
\text { available to the teacher } \\
\text { - types of situations }\end{array}$ & $\begin{array}{l}\text { Event: Aware } \rightarrow \\
\text { isolated v. integrated } \\
\text { Source of problem: } \\
\text { - learning engagement of } \\
\text { students } \\
\text { - behavioral issue of } \\
\text { student(s) } \\
\text { - role and influence of } \\
\text { teacher }\end{array}$ & $\begin{array}{c}\text { Mediated by } \\
\text { teachers' } \\
\text { knowledge \& } \\
\text { experiences in } \\
\text { the classroom }\end{array}$ & $\begin{array}{l}\text { - respond to precursors } \\
\text { (predictive + proactive) } \\
\text { - address consequences } \\
\text { (familiar type of situation: } \\
\text { aware + reactive) }\end{array}$ \\
\hline
\end{tabular}

Fig. 2 Structural differences in expert and novice teachers' knowledge - their classroom management scripts - and decisions to act in response to classroom events

actors, i.e., what they notice with their eyes. Perception is a precondition for the ongoing thought-processing that supports teachers' interpretations of classroom events. In this article, it is synonymous with the verb "to see."

- Interpretation refers to how teachers analyze and make sense of what they notice in relation to their teaching and learning goals (Van Es and Sherin 2002). Interpretation relies on activating/having/using knowledge about the context of classroom events to reason about and make sense of classroom situations.

- Situational awareness refers to teachers' knowledge of what is happening in real-time in the classroom, implying both knowledge gained through immediate, sensory perception as well as the stored episodic knowledge acquired through experience working in classrooms. Teachers' situational awareness unifies perceptions and interpretation of events, supporting their ability to project how events will unfold and decisions about whether or not to take action in teaching situations.

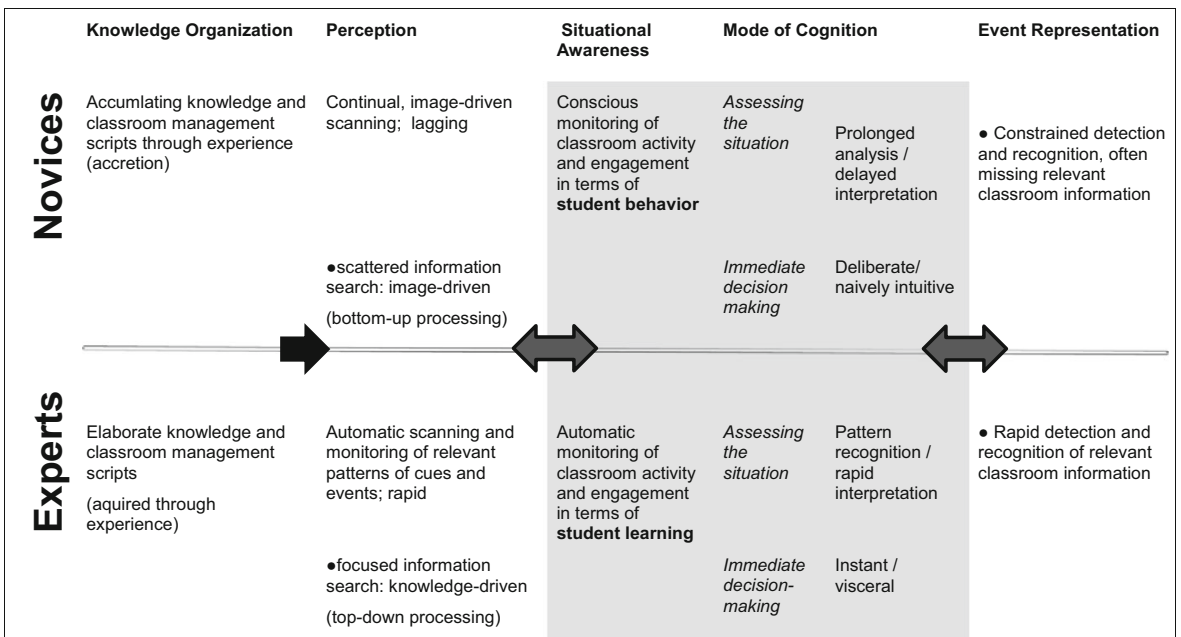

Fig. 3 The influence of activated classroom management scripts on expert and novice teachers' situational awareness, mode of cognition, and event representation 
- Withitness describes the skill through which teachers process and handle classroom situations, underlining two important dimensions to teachers' classroom awareness: (1) what the teacher sees and hears in order to interpret what is happening; and (2) what the teacher does in a situation and how they decide to act in order to sustain learning.

- A classroom event is defined as any activity occurring in the classroom that involves one or more people, is considered noteworthy by the observer, and has duration within the mind of the observer - i.e., a perceptible start and endpoint in the mind of the teacher. A classroom situation is defined as a series of interconnected events.

- Teachers' professional vision is defined as teachers' skillfulness at observing classroom situations, noticing relevant features and events, and making sense of classrooms (Goodwin 1994; Van Es and Sherin 2002).

Professional vision relies predominantly on teachers' visual perception of events/situations in combination with their ability to activate and apply existing knowledge to interpret what they perceive. Teaching experience influences professional vision in a number of ways. It affects how teachers direct attention to relevant elements of classroom events and situations related to instruction and learning (Seidel and Stürmer 2014). It strongly influences how teachers integrate and respond to the events they observe (Hattie 2012; Livingston and Borko 1989; Sabers et al. 1991). It affects which events teachers perceive and attend to, how these are transformed into meaningful interpretations of what is happening in the classrooms, and their predictions about what may happen next (Colestock and Sherin 2009; Zacks et al. 2007). Any given situation in the classroom affords a range of possible interpretations (Bruner 2003). A teacher must first identify the importance of events before integrating their knowledge of events with their ongoing perceptions to holistically interpret the situational context and meaning of events (Berliner 1988). Information from current classroom events combines with memories (stored episodic knowledge) of previous classroom experiences so that a teacher can develop a plausible interpretation, create goals and expectations, and make predictions about events that are likely to follow or that may require further observation (Carter and Doyle 1987).

Although events consist of fleeting, multi-sensory input, people's ongoing mental processing tends to process them as stable entities with discrete parts - episodes - that form the basis of perception, attention, and memory (Zacks et al. 2007). Expert teachers have elaborate episodic knowledge of classrooms, are better able to adaptively integrate their pedagogical knowledge of types of events and students, and are more perceptive to the multidimensional complexity of classroom events (Berliner 2001; Doyle 1990; Westerman 1991). A noted difference between expert and novice teachers is the manner in which they interpret what occurs in classrooms, and how they consciously deliberate and reflect upon classroom events (Bromme 2001; Copeland et al. 1994; Tsui 2003). Expert teachers see and explain things that novices are hesitant or unable to describe.

\section{Classroom Management and Teacher Expertise}

As our theoretical approach builds upon an expert-novice paradigm, it is useful to review how teachers' knowledge for classroom management differs according to expertise. When we speak of classroom management, by definition, we are referring to all actions teachers take to create, facilitate, and maintain an effective learning environment. As a system centered around supporting student learning, it relies to a large extent on perceptive teaching that 
predicts and prevents problems in the classroom, and to a lesser extent on disciplinary actions addressing disruptive student behavior (Bear 2015; Brophy 2006). In other words, successful teaching that leads to successful student learning depends upon successful management decisions. This ability to manage actors and events to support learning goals requires extensive knowledge of classroom phenomena-i.e., the dynamic events and human interplay arising in classrooms - and an ability to discern between relevant and irrelevant events, deciding which require attention and which do not (Berliner 1988; Carter et al. 1988; Emmer and Stough 2001; Palmer et al. 2005; Schempp et al. 1998; Shulman 2000).

Practically speaking, the main goal of classroom management is to optimize classroom learning, and a secondary goal is minimizing events that are disruptive to learning. Expert and novice teachers' processing of classroom events differs in several key ways. For example, when commenting on classroom events, expert teachers assign deeper meaning to classroom events, and their perceptions are more analytical and comprehensive; novices typically describe events in detail, but offer little evidence of deeper thought or analysis (Sabers et al. 1991). Expert teachers also tend to focus less on disruptive student behavior than novices, partially because they are able to prevent disruptions by recognizing behavioral and event cues early on and adjust their teaching activities accordingly and partially because they are more concerned with learning consequences than misbehavior (Westerman 1991; Wolff et al. 2017). Novices are less selective about the cues and events they attend to because they are still developing mental strategies that would allow them to make sense of the complexity typical to classrooms, whereas experts have response patterns well suited to the demands of the classroom (Doyle 1977; Wolff et al. 2015). Differences in both the quality and depth of teachers' knowledge are linked to differences in how expert and novice teachers represent and process classroom management events.

\section{Classroom Management Scripts}

Teachers' ability to interpret what happens depends on their representations of events and the relationships between events, i.e., ongoing classroom situations. This relies on their mental representations, defined as the transient, temporary mental imagery, constructions, and interpretations of objects and events in the classroom (Hogan et al. 2003). Teachers' knowledge of classroom events and the patterns inherent to the types of events and situations occurring within classrooms are built up over time as teachers accumulate knowledge. Over the long-term, this knowledge is reorganized and restructured through experience, changing as new knowledge about events and situations is added and the corresponding cognitive scripts are acquired. The value of accrued knowledge should not be underestimated. "People need a great deal of knowledge in order to understand. That knowledge can be of two kinds: specific and general. Scripts are intended to account for the specific knowledge that people have. Most of understanding is script-based" (Schank and Abelson 1977, p.67).

A script refers to the generalized knowledge one has about particular types of frequently encountered situations, including the actors involved as events unfolded in a particular time and in a particular place. Scripts aid in understanding what we see and experience, making sense of what others are saying and doing, predicting what will happen next, and organizing memories of our experience (Schank 2007). Despite their domain-specificity, similarities in tasks, events, and information processing appear to result in similarities in knowledge structures across domains (Boshuizen et al. 2020). In the professional domain of teaching, scripts 
provide the background knowledge that helps teachers understand the complex world of the classroom and they expand as teachers learn through experience in the classroom. Scripts provide connectivity between events and are more tightly connected to specific types of events than to the overarching situations. Teachers' ability to recognize the relevance of different events is crucial to their knowledge acquisition. Whenever an existing script is violated or expectations (about actors and events) are challenged, teachers' scripts are rewritten and their knowledge is restructured accordingly.

Classroom management scripts refer to specific knowledge structures comprising a common sequence of events necessary to achieve management goals in the classroom, including relevant actors, spatial locations, physical objects, and how these interact as events play out (Bromme 2001; Schank and Childers 1984; Zacks et al. 2007). They develop through exposure to numerous events and varied experiences in the classroom. Scripts framed around classroom events are important for perceiving and organizing visual information, influencing perceptual attention, subsequent interpretation of sensory input, and determining actions within classroom situations as a whole (Henderson 2011; Leinhardt and Greeno 1986). The basic construct of a classroom management script comprises enabling conditions, the classroom event representation, and the consequences associated with the event (Fig. 1).

Classroom management scripts serve as a (theoretical) basis for how teachers interpret classroom events and how they decide to respond to potential and actual management issues in the classroom. With familiar types of classroom events, one prominent script - and possibly related scripts - is activated as a whole. This enables quick predictions about what is likely to follow, in a sense offering an internalized suggestion about how to manage an event and the situation-specific consequences associated with it. The script simultaneously controls information processing and represents the situation.

While experts have the benefit of an abundance of experience-enriched classroom management scripts to guide their event representation and subsequent actions, novices cannot draw from such a deep well of professional knowledge and experience. Instead, novices are still engaging in a vital stage of knowledge accretion. Similarly, experts' knowledge is not inert - it also transforms and restructures through additional experience. Novices, however, are actively developing and building the knowledge structures that will serve to guide and inform their practice as they acquire expertise. Hence, the varying richness of teachers' classroom management scripts is distinguished by novices' being in formation whereas experts' are already established through experience (Boshuizen and Schmidt 2008). To clarify the structural components of classroom management scripts, we will move from the left to the right of Fig. 2 to unpack the theoretical model.

\section{Enabling Conditions}

One script component consists of enabling conditions: the contextual background factors (conditions and constraints) influencing the probability that particular classroom events will occur. This includes the classroom environment, the composition, age, personality traits of the students, the content being taught, and the teaching techniques being used. Perception of enabling conditions relies on merging external factors - the sensory input from the classroom - with internal factors - event representations and subsequent interpretations of this sensory input. External and internal factors combine to form an integrated awareness of the situation, guiding thinking about what could or should be done in response to input (Boshuizen 
and Schmidt 2008). As shown on the left of Fig. 2, experts' recognition of enabling conditions are primed by diverse knowledge of students, assessment of student learning, ample understanding of the dynamics of classroom interactions, a wide range of pedagogical options available to teachers, and clear characterizations of situations that frequently occur in classrooms. Knowledge structures supporting novices' recognition of enabling conditions are minimal in comparison with that of experts, largely due to their limited professional experience in the classroom context.

By way of example, if a teacher is giving a boring lesson, has not ensured that all students have learning materials, and allows distracting behavior to go unchecked, these constitute enabling conditions with a number of potential consequences. Consider an event where one student starts gesturing towards another. The distracting gestures are likely to catch the attention of the intended recipient as well as a number of other students witnessing the movements. Ignoring off-task behavior of one student often sends a message to other students that they are similarly free to do as they please. Gradually, lack of engagement in the lesson may spread across the classroom, and students may begin to pursue their own priorities and pass the time in ways that have little to do with their teacher's goals for the lesson.

The concept of enabling conditions in the context of scripts was introduced by Feltovich and Barrows (1984) in the domain of medicine, where it describes similar kinds of conditions that affect the possibility of occurrence of certain diseases. In addition to the conceptual similarity applied to our model of classroom management scripts, empirical similarity also exists between the medical and teaching domains, as novices in both professions appear to have poor knowledge of/for enabling conditions and — as a consequence - do not recognize precursors of potentially problematic or harmful situations (see Custers 2015).

\section{Consequences}

Accordingly, another script component consists of the pedagogical consequences of the problem: signals, and (potential) sources of problems associated with an event that may require action/intervention to manage. Consequences are linked to teachers' perception of an event, their interpretation of links to prior events and actors involved, and their predictions about its potential to become problematic and require action. For novices, consequences are framed in terms of whether or not they perceive and interpret the relevance of events. Novices are often not fully aware of input that would engage scripts, as novices have been shown to miss the signals and events that experts find meaningful and informative (Carter et al. 1988; Chi 2006; Copeland et al. 1994; van den Bogert et al. 2014; see also Custers 2015 for the medical parallel). Novices' representation of events tend to place emphasis on student behavior, and they often cite students as the source of problems. In contrast, experts put more emphasis on the quality of learning, considering both students and the teacher as potential sources of problems in relation to events (Wolff et al. 2015).

When a classroom management script is activated, the degree to which the consequences of the event are clear to novices affects their mental representation. For this reason, novices' identification of the source is relatively binary: either the source is clear or unclear. If it is clear, most likely it is linked in their minds to some behavioral digression of the students, or possibly to dwindling engagement levels of students. Experts' deliberation about events is more analytical and interpretative. Their episodic knowledge of events helps them maintain a general perceptual awareness focused on student engagement and learning and whether or not pedagogical goals are being attained (Wolff et al. 2016). For experts, an event may be 
interpreted as either occurring in isolation-disconnected from other events arising in the classroom - or as integrated with other interactions and events. When attributing a source to a classroom problem, they activate considerations related to both behavioral and learning concerns, factoring in the role and influence of the teacher in the context of the situation (Wolff et al. 2015).

\section{Classroom Event Representation}

If a classroom management script is activated, i.e., instantiated, the enabling conditions and consequences converge to form the classroom event representation: the understanding of what is actually happening in the classroom situation and what, if any, action is required (cf. the "fault" in the script model of Boshuizen and Schmidt 2008). This event representation is crucial to the ongoing assessment of the situation, and it drives the structuring and restructuring of teachers' scripts. This, in turn, guides the recurring, continual cycle of perception and interpretation as a situation develops and moves forward through time and space. As opposed to the knowledge structures of scripts that build up over the long term, the event representation is more transient and short term, and is updated as a teacher detects and monitors pertinent classroom input. Nonetheless, this transient representation is dependent on teachers' knowledge of pedagogy, students, subject matter, and the factors constituting an appropriate learning environment. This is what is meant by teachers" "knowledge and experience in the classroom" mediating their representation of classroom events.

In contrast to novices, expert teachers possess elaborate knowledge about types of events occurring in classroom situations (Hogan et al. 2003). Experts perceive classroom situations in terms of groups of students rather than primarily focusing on individual students, whereas novices devote more visual attention to individual students (van den Bogert et al. 2014). For example, if one student is gesturing wildly to get another students' attention instead of completing a worksheet, an expert is likely to consider whether or not students sitting in front, behind, and to the side are being led off-task, rather than focusing on the single student causing the disruption. Novices are likely to dwell more on the single student. Experts actively scan both teacher and student actions as they monitor classroom dynamics, while novices primarily perceive events from the teachers' point of view (Sabers et al. 1991). Using the same example above, an expert is likely to consider the actions of the teacher prior to and in response to the gesturing, while also factoring in relationships and interactions between students in their accounting of events across time. A novice is likely to place the blame solely on the distracting student. To repeat a point made earlier, the centrality of student learning is key to experts' interpretation of events, whereas novices' emphasize behavioral concerns, attributing problems to actions of students as opposed to the actions (or in-action) of the teacher (Tsui 2009; Authors).

\section{Decision to Act}

More importantly for teaching practice, event representation directly relates to teachers' decision to act in a given situation. The elaborate knowledge scripts of expert teachers make it possible for them to respond to classroom situations either predictive/proactive or aware/ reactive manner that is rooted in their familiarity with typical events. A predictive response is based on the perception of precursors, i.e., the signals perceived before an event has escalated into a full-blown disruptive situation demanding the full attention and resources of the teacher. 
Being predictive relies on the detection of nuanced, contextualized cues characterizing the early stages of an event. Rapid detection allows for time to be proactive towards preventing the escalation of a problem. A reactive response can take into account these precursors, but differs from a predictive response in that it involves reacting to an event that has become pedagogically problematic in real-time, as opposed to an event which is only potentially problematic. When experts react to classroom events, enabling conditions have been foreseen and perceived as a familiar type of situation, and the decision to act is a reaction to this predictive perceptual awareness.

Unable to dip into the well of knowledge informing experts' decisions to act, novices' decisional options are more limited. As explained earlier, novices' event perception is hindered, as they have yet to accumulate a store of relational knowledge linking situational signals and events. Novices are either aware of a problem (likely an overt disruption) that demands their attention, or they are blissfully unaware of such an event. This means that they may overlook information that experts account for, constraining their ability to decide on appropriate/suitable actions to take. They may ignore an event and its consequences because they are unable to interpret its meaning, or because the situation is precarious, and decisions to act are riddled with uncertainty. Or, alternatively, they may perceive an event and decide to react to the situation, engaging existing scripts.

\section{The Influence of Classroom Management Scripts and Expertise on Teachers' Awareness of Classroom Events and Situations}

While Fig. 2 shows how novice and expert teachers differ in terms of the structure and activation of classroom management scripts, Fig. 3 depicts how classroom management scripts influence teachers' visual perception, situational awareness, mode of cognition, and event representation.

A teacher's awareness of classroom situations is a powerful cognitive tool for interpreting classroom events and managing classroom interactions. Kounin (1970) coined the term withitness to describe teachers' ability to maintain and communicate an awareness of what is happening in the classroom at any given moment. Withitness captures the skill through which teachers process and handle classroom situations, underlining two important dimensions to teachers' classroom awareness: (1) what the teacher sees and hears - scanning and monitoring the classroom to perceive valuable information for understanding and interpreting what is happening; and (2) what the teacher does in a situation-deciding to act in ways which sustain learning and convey an astute understanding of unfolding events to the students. But how do teachers pull off this cognitive feat that amounts to withitness?

We turn to Endsley's $(1995,2006)$ theory of situational awareness to explain the cognition that reinforces and helps teachers attain classroom withitness. Situational awareness has been shown to play a crucial role in professional domains where there are multiple factors to attend to and monitor, particularly when these factors can change rapidly and interact together in complicated ways. There are three levels to situational awareness: (1) perception, which relies on the intake of environmental input; (2) comprehension, which requires that a person understands the meaning and relevance of the perceived information; and (3) projection, which is the ability to predict the dynamic implications of current events and anticipate future events.

The quality of situational awareness has also been shown to differ based on expertise (Endsley 2006). Based on teacher expertise differences outlined earlier, our model presumes that novices typically become overloaded in their efforts to perceive information, understand 
its meaning, and respond appropriately. Moreover, their understanding of what is relevant and significant in a situation is often inefficient and error prone. This is mainly attributed to their lack of an experiential basis for interpreting professional situations and the limitations this imposes on their attention and working memory. Experts, however, have already developed knowledge that we presume take the form of appropriate scripts for maintaining an effective awareness of a situation without the impediments characterizing novices. They have numerous scripts for typical events within the larger system of classroom management, and this knowledge helps guide their perceptual attention more efficiently. These classroom management scripts support integration of differing internal and external situational factors that transform into efficient, meaningful interpretations of perceptual input. This integrated awareness fuels teachers' ability to monitor events, notice enabling conditions, project future events, and determine appropriate actions to manage the classroom. This awareness equates to withitness, and such ongoing, well-integrated situational awareness is the baseline for teachers' professional vision.

Again, our explanation of the model proceeds from left to right, although the model itself is not entirely linear, as indicated by the arrows in the model. It is worth noting that situational awareness is tightly coupled with mode of cognition (explained below), so these components are grouped together. Perception and event representation interact with these components in a recurring loop of input and interpretation as ongoing perceptual processing updates cognizance of events - i.e., situational awareness - which impacts the pace of event detection-i.e., mode of cognition-and the meaning attached to classroom events.

\section{Knowledge Organization}

Teachers' knowledge organization influences perception and ensuing situational awareness, i.e., how classroom events are perceived, interpreted, and projected. Figure 2 has already illustrated how classroom management scripts (the structural organization of teachers' knowledge) acquired through experience influence event representation. As teachers scan and search the classroom for information, ongoing internal factors have an influence on all components of the model in Fig. 3, while external factors (of sensory input from the classroom environment) particularly impact perception and mode of cognition (Eraut 2007).

\section{Perception}

Recent research has demonstrated that experts' visual attention can be characterized as a focused, knowledge-driven search for external classroom information, while novices' visual attention is more scattered and indiscriminate, characterized by image-driven processing (Wolff et al. 2016). Novices' eye movements were shown to be strewn across many potentially relevant events in the classroom, resulting in a scattered search for information that was driven by visually salient features of the classroom. Consequently, novices' perceptions may lag as they struggle to keep up with the flow of interactions. Experts' eye movements were shown to disperse in a rapid, focused search for relevant events that was driven by their knowledge and projections. They repeatedly monitored areas of the classroom displaying interactions between students. These findings suggest that internal factors, i.e., the knowledge driving teachers' perception, take priority over the external factors accounted for in teachers' perception and corresponding event representation. 


\section{Situational Awareness and Mode of Cognition}

The knowledge driving teachers' thinking is shaped and structured in relation to the tasks and activities encountered specifically in the classroom, and how teachers make sense of classroom situations “. $\ldots$ is a product of ordered prior knowledge of classroom scenes, awareness of particular features of a present scene, and cognitive processes that connect knowledge with current awareness" (Carter and Doyle 1987, p.149). Much of teachers' situational awareness is concentrated on processing signals from students, especially determining what they are thinking and learning and what types of interactions are taking place (Gaudin and Chaliès 2015).

From the perspective of management, classrooms are crowded and busy places in which groups of students who vary in interests and abilities must be organized and directed. Moreover, these groups assemble regularly for long periods of time to accomplish a wide variety of tasks. Many events occur simultaneously, teachers must react often and immediately to circumstances, and the course of events is frequently unpredictable. Teaching in such settings requires a highly developed ability to manage events." (Doyle 1990, p.350)

Awareness (withitness) demands continual interactional monitoring: knowing what is happening with and between students - accompanied by their understanding of student-to-teacher interactions, such as when students directly respond or communicate with the teacher and vice versa. Knowledge gleaned from experience guides both monitoring and making sense of classroom activity.

The speed of events, the varying actors, and the countless interpretative possibilities of classroom interactions are notoriously challenging aspects of the teaching profession. Although novices, like experts, possess knowledge of pedagogy, students, subject matter, and the classroom environment, the structuring and accessibility of their knowledge are constrained by their limited classroom experience, hindering their ability to differentiate between relevant and non-relevant events (Doyle 2006; Tsui 2003; Wolff et al. 2016). Their awareness is often singularly focused on the behavior of students and the degree to which the behavior they are viewing complies or conflicts with their expectations of acceptability (Wolff et al. 2017). Novices may also be limited by an inability to consider classroom situations from the students' point of view, an important component of teachers' professional vision, and a potential blind spot for making management decisions that enhance student learning (Colestock and Sherin 2009; Wolff et al. 2015). Expert teachers are noted for their ability to manage the complexities of teaching almost effortlessly. Their efficient, automatized monitoring of activities means that they do not need to actively contemplate or deliberate in typical situations. The fast-paced context of classroom events bears heavily on how teachers sort out what is relevant from what is irrelevant, and how they process competing informational input (Haider and Frensch 1996).

To outline expertise differences in the processing time available to experts and novices, we draw on Eraut's (2007) theory of workplace learning to address the mode of cognition applicable to the conditions and cognitive demands of the classroom. All teachers are confronted with the multidimensionality and simultaneity of classroom events - many actions and events occurring at the same time - and the immediacy of classroom situations, which demand decisions and reactions in the here and now (Doyle 2006; Sabers et al. 1991). All teachers must assess a situation and make decisions about what to do, but the mode of 
cognition through which classroom events are perceived and interpreted diverges between novice and expert teachers. First, experts can lean on their rapid processing of information, affording them more time to react to events. Since the boundaries of events - when an event begins and ends - are in the eyes of the beholder, and, as explained earlier, experts predict upcoming events earlier than novices, experts have more time to align event awareness with more thoroughly informed interpretations of the ensuing situation (Zacks et al. 2007). Second, the "crowdedness of the situation," such as the intensity and volume of signals and events, the number of students and their varying levels of engagement, the achievement of learning goals, and other considerations compete for teachers' attention. This necessarily impacts how quickly classroom situations and corresponding problems can be processed, as well as which events receive attention (Eraut 2004). Lacking the knowledge structures that allow speedy assessment of the situation, novices will revert to prolonged analysis and delayed interpretation of isolated pieces of information, meanwhile missing other relevant information. That is, novice teachers are not able to act in the instant and professionally reflective ways required by teaching situations as experts do.

\section{Event Representation}

Integrating and inter-relating relevant internal and external factors during the act of teaching requires continually assessing and re-assessing events, including how progressing events encompassed relate to the situation as a whole. As teachers' management scripts for specific classroom situations and events are activated, a routine, automatized response particular to the situation at hand comes into play. The more accurately a teacher anticipates events, the smaller the range of actions applied in response. Experts' assessing of classroom situations involves almost immediate pattern recognition, leading to rapid interpretations, and their scripts inform the immediate decision-making that is instantaneous and visceral, arising without deliberative thought. For novices, the multidimensionality, simultaneity, and immediacy demanded in the classroom can be cognitively overwhelming. Without classroom management scripts to aid interpretation, sorting through the dizzying amount of competing information becomes a difficult mental activity, and perceptions can be constrained by the lack of time available for the necessary information processing. In our model, novices' assessing is characterized as a more prolonged, deliberate analysis. Their ability to keep track of events may not keep up with the rapid flow of information, resulting in constrained detection and incomplete awareness of the situation. Novices must continue their teaching performance without being able to fully interpret or understand events in the situation at hand. Representations may arrive too little too late, allowing events to escalate into fullblown management problems. Immediate decision-making is similarly slowed down by the deliberate, rational thought-processing, relying on a naïve, budding intuition that may impede decisions to act and result in ineffective management solutions.

\section{Implications of Classroom Management Scripts for Teacher Preparation and Practice}

Determining which events and situations require action relies to a great extent on teachers' knowledge structures (i.e., the classroom management scripts described in Fig. 2), which allow teachers to ascribe meaning to their perception of events and project these interpretations upon future states of the classroom situation. 
Deciding when and how to pursue a particular course of action depends on teachers' situational awareness. The model in Fig. 3 captures the influence classroom management scripts exert on teachers' withitness: their awareness of classroom events and ensuing situations and their decisions about whether or not, and when, action is required. Genuine withitness requires recognizing a situation in terms of what it means for teaching and understanding how it relates to managing learning en masse.

Episodic knowledge of classroom events plays a powerful role in teachers' situational awareness. It affects the following: (1) how teachers perceive and devote attention to specific signals and events; (2) what they identify as causal and contributing factors involved in a situation; and (3) how they project and relate this information to issues of learning and classroom management. Teachers' in situ interpretations of events guide their ongoing perceptual intake of new information to confirm or update understanding as events continue to unfold. Ex post facto interpretations also support teachers' thinking when they take time to reflect and reason about what happened in a particular situation and how it relates to teaching practice. Considering the models proposed in this article in light of their potential to influence teacher training and development of professional vision underscores their applicability to teaching practice.

By characterizing general differences between expert and novice classroom management scripts and their influence on awareness, we have underlined ways in which beginner teachers' situational awareness must be developed to approach that of experts. For example, making new teachers aware that enabling conditions can be rather subtle, and reframing classroom management as a learning concern rather than a behavioral concern is an area that teacher education programs could explore more thoroughly with beginner teachers. Reinforcing the agency and influence of teachers on classroom situations may aid novices in overcoming the tendency to finger students as the cause of problems.

Given the visual nature of classroom events, the role of classroom management scripts can be considered when designing training activities to improve both perception and interpretation of classroom situations. Designing training videos which utilize experts' ways of seeing and thinking about classroom events can support novices as they learn to analyze and make sense of complex classroom situations. Drawing attention to the signals and events that experts consider relevant - i.e., the features and factors which inform their professional vision - can help set goals for novices about the kind of information they need to be vigilant about. Exposing teachers-in-training to experts' interpretations may help heighten withitness by supporting the three levels of situational awareness: their perceptual, comprehension, and projection capabilities. Applying this model of how knowledge influences teachers' situational awareness in both research and practice aids in creating specific, practice-based focal points to alleviate the complexity of managing the classroom environment.

\section{Conclusion}

In this article, we proposed a two-part theoretical model by (1) characterizing the knowledge structures of expert and novice teachers' for processing events - classroom management scripts - and (2) describing the influence these scripts have on teachers' situational awareness in the classroom. The model developed here begins to clarify how teachers organize their knowledge and perceive and interpret classroom events, and how experience mediates these aspects of teacher cognition. It suggests that focusing on goals of learning rather than behavior 
can alter the interpretations of events by exposing how teachers maintain withitness and how differing levels of experience informs teachers' professional vision for classroom events.

As Hattie (2012) explains, "Learning is not always pleasurable and easy; it requires overlearning at certain points, spiraling up and down the knowledge continuum, building a working relationship with others in grappling challenging tasks" (p.20). While there is no substitute for the practical knowledge that teachers develop through their own classroom experience, making teachers more attentive to general expert-novice patterns in the perception and interpretation of classroom events can help steer development of their classroom management expertise, either through teacher training or personal professional reflection. We are optimistic that the model presented here can contribute to the knowledge continuum supporting teachers and teacher educators as they grapple with the unceasing complexity of managing the classroom.

Acknowledgments The authors gratefully acknowledge the insightful and attentive advice provided by Dr. Teitur Jónsson that contributed to significant improvements in the structure and clarity of the manuscript.

\section{Compliance with Ethical Standards}

Conflict of Interest The authors declare that they have no conflict of interest.

Open Access This article is licensed under a Creative Commons Attribution 4.0 International License, which permits use, sharing, adaptation, distribution and reproduction in any medium or format, as long as you give appropriate credit to the original author(s) and the source, provide a link to the Creative Commons licence, and indicate if changes were made. The images or other third party material in this article are included in the article's Creative Commons licence, unless indicated otherwise in a credit line to the material. If material is not included in the article's Creative Commons licence and your intended use is not permitted by statutory regulation or exceeds the permitted use, you will need to obtain permission directly from the copyright holder. To view a copy of this licence, visit http://creativecommons.org/licenses/by/4.0/.

\section{References}

Ball, D. L., \& Forzani, F. M. (2009). The work of teaching and the challenge for teacher education. Journal of Teacher Education, 60(5), 497-511. https://doi.org/10.1177/0022487109348479.

Bear, G. (2015). Preventative and classroom-based strategies. In E. Emmer \& E. Sabornie (Eds.), Handbook of classroom management (2nd ed., pp. 15-38). Routledge.

Berliner, D. (1988). The development of expertise in pedagogy. American Association of Colleges for Teacher Education.

Berliner, D. (2001). Learning about and learning from expert teachers. International Journal of Educational Research, 35(5), 463-482. https://doi.org/10.1016/S0883-0355(02)00004-6.

Berliner, D. (2004). Describing the behavior and documenting the accomplishments of expert teachers. Bulletin of Science, Technology and Society, 24(3), 200-214.

Berry, B., Daughtrey, A., \& Wieder, A. (2010). Preparing to lead an effective classroom: the role of teacher training and professional development programs. Center for Teaching Quality. http://teachersnetwork. org/effectiveteachers/images/CTQPolicyBriefOn_TCHR_TRAINING_ANDPROFDEV_021810.pdf

Boshuizen, Henny. P. A., \& Schmidt, H. G. (2008). The development of clinical reasoning expertise; Implications for teaching. In J. Higgs, M. Jones, S. Loftus, \& N. Christensen (Eds.), Clinical reasoning in the health professions (3rd ed., pp. 113-121). Butterworth-Heineman/ Elsevier.

Boshuizen, H. P. A., Gruber, H., \& Strasser, J. (2020). Knowledge restructuring through case processing: The key to generalise expertise development theory across domains? Educational Research Review, 29, 100310. https://doi.org/10.1016/j.edurev.2020.100310.

Bromme, R. (2001). Teacher expertise. In N. Smelser \& P. Baltes (Eds.), International encyclopedia of the behavioral sciences: Vol. Education (pp. 15459-15465). Pergamon. 
Brophy, J. (2006). History of research on classroom management. In C. Evertson \& C. Weinstein (Eds.), Handbook of classroom management: research, practice and contemporary issues (pp. 17-43). Erlbaum.

Bruner, J. S. (2003). The culture of education (7th print). Harvard University Press.

Carter, K., \& Doyle, W. (1987). Teachers' knowledge structures and comprehension processes. In J. Calderhead (Ed.), Exploring teachers' thinking (pp. 147-160). Cassell.

Carter, K., Cushing, K., Sabers, D., Stein, P., \& Berliner, D. (1988). Expert-novice differences in perceiving and processing visual classroom information. Journal of Teacher Education, 39(3), 25-31. https://doi. org/10.1177/002248718803900306.

Chi, M. (2006). Two approaches to the study of experts' characteristics. In K. A. Ericsson, N. Charness, P. Feltovich, \& R. Hoffman (Eds.), The Cambridge handbook of expertise and expert performance (pp. 2130). Cambridge University Press.

Colestock, A., \& Sherin, M. G. (2009). Teachers' sense-making strategies while watching video of mathematics instruction. Journal of Technology and Teacher Education, 17(1), 7-29.

Copeland, W. D., Birmingham, C., DeMeulle, L., D’Emidio-Caston, M., \& Natal, D. (1994). Making meaning in classrooms: an investigation of cognitive processes in aspiring teachers, experienced teachers, and their peers. American Educational Research Journal, 31(1), 166-196. https://doi.org/10.3102 /00028312031001166.

Custers, E. J. F. M. (2015). Thirty years of illness scripts: theoretical origins and practical applications. Medical Teacher, 37(5), 457-462. https://doi.org/10.3109/0142159X.2014.956052.

Darling-Hammond, L. (2006). Constructing 21st-century teacher education. Journal of Teacher Education, 57(3), 300-314.

Doyle, W. (1977, April). Learning the classroom environment: an ecological analysis of induction into teaching. Annual Meeting of the American Educational Research Association.

Doyle, W. (1990). Classroom knowledge as a foundation of teaching. Teachers College Record, 91(3), 347-360.

Doyle, W. (2006). Ecological approaches to classroom management. In C. Evertson \& C. Weinstein (Eds.), Handbook of classroom management: research, practice and contemporary issues (pp. 97-125). Erlbaum.

Emmer, E., \& Stough, L. (2001). Classroom management: a critical part of educational psychology with implications for teacher education. Educational Psychologist, 36(2), 103-112. https://doi.org/10.1207 /S15326985EP3602_5.

Endsley, M. (1995). Toward a theory of situation awareness in dynamic systems. Human Factors, 37(1), $32-64$.

Endsley, M. (2006). Expertise and situation awareness. In K. A. Ericsson, N. Charness, P. Feltovich, \& R. Hoffman (Eds.), The Cambridge handbook of expertise and expert performance (pp. 633-651). Cambridge University Press.

Eraut, M. (2004). Informal learning in the workplace. Studies in Continuing Education, 26(2), $247-273$. https://doi.org/10.1080/158037042000225245.

Eraut, M. (2007). Learning from other people in the workplace. Oxford Review of Education, 33(4), 403-422. https://doi.org/10.1080/03054980701425706.

Feltovich, P., \& Barrows, H. (1984). Issues of generality in medical problem solving. In Tutorials in ProblemBased Learning (pp. 128-142).

Gaudin, C., \& Chaliès, S. (2015). Video viewing in teacher education and professional development: a literature review. Educational Research Review, 16, 41-67. https://doi.org/10.1016/j.edurev.2015.06.001.

Goodwin, C. (1994). Professional vision. American Anthropologist, 96(3), 606-633.

Haider, H., \& Frensch, P. A. (1996). The role of information reduction in skill acquisition. Cognitive Psychology, 30(3), 304-337. https://doi.org/10.1006/cogp.1996.0009.

Hattie, J. (2012). Visible learning for teachers: Maximizing impact on learning. Routledge.

Henderson, J. (2011). Eye movements and scene perception. In S. P. Liversedge, I. D. Gilchrist, \& S. Everling (Eds.), The Oxford handbook of eye movements (pp. 593-606). Oxford University Press.

Hogan, T., Rabinowitz, M., \& Craven III, J. (2003). Representation in teaching: inferences from research of expert and novice teachers. Educational Psychologist, 38(4), 235-247.

Kounin, J. (1970). Discipline and group management in classrooms. Rinehart and Winston.

Leinhardt, G., \& Greeno, J. G. (1986). The cognitive skill of teaching. Journal of Educational Psychology, 78(2), 75-95. https://doi.org/10.1037/0022-0663.78.2.75.

Livingston, C., \& Borko, H. (1989). Expert-novice differences in teaching: a cognitive analysis and implications for teacher education. Journal of Teacher Education, 40(4), 36-42. https://doi.org/10.1177 /002248718904000407.

McMahon, M., Forde, C., \& Dickson, B. (2015). Reshaping teacher education through the professional continuum. Educational Review, 67(2), 158-178. https://doi.org/10.1080/00131911.2013.846298.

Palmer, D., Stough, L., Burdenski Jr., T., \& Gonzales, M. (2005). Identifying teacher expertise: an examination of researchers' decision making. Educational Psychologist, 40(1), 13-25. https://doi.org/10.1207/s15326985 ep4001_2. 
Sabers, D., Cushing, K., \& Berliner, D. (1991). Differences among teachers in a task characterized by simultaneity, multidimensionality, and immediacy. American Educational Research Journal, 28(1), 63-88.

Schank, R. (2007). Scripts. In Encyclopedia of Social Psychology: 2 (Vol. 2, pp. 727-728). Sage.

Schank, R. C., \& Abelson, R. P. (1977). Scripts, plans, goals and understanding: an inquiry into human knowledge structures. Psychology Press.

Schank, R. C., \& Childers, P. G. (1984). The cognitive computer: on language, learning, and artificial intelligence. Addison-Wesley Pub. Co.

Schempp, P., Tan, S., Manross, D., \& Fincher, M. (1998). Differences in novice and competent teachers' knowledge. Teachers and Teaching, 4(1), 9-20. https://doi.org/10.1080/1354060980040102.

Seidel, T., \& Stürmer, K. (2014). Modeling and measuring the structure of professional vision in preservice teachers. American Educational Research Journal, 51(4), 739-771. https://doi.org/10.3102 $/ 0002831214531321$.

Shulman, L. (2000). Teacher development roles of domain expertise and pedagogical knowledge. Journal of Applied Developmental Psychology, 21, 129-135. https://doi.org/10.1016/S0193-3973(99)00057-X, 1.

Spalding, E., Klecka, C., Lin, E., Wang, J., \& Odell, S. J. (2011). Learning to teach: it's complicated but it's not magic. Journal of Teacher Education, 62(1), 3-7. https://doi.org/10.1177/0022487110384196.

Tatto, M. T., Richmond, G., \& Carter Andrews, D. J. (2016). The research we need in teacher education. Journal of Teacher Education, 67(4), 247-250. https://doi.org/10.1177/0022487116663694.

Tsui, A. (2003). Understanding expertise in teaching: case studies of second language teachers. Cambridge University Press.

Tsui, A. (2009). Distinctive qualities of expert teachers. Teachers and Teaching: Theory and Practice, 15(4), 421-439. https://doi.org/10.1080/13540600903057179.

van den Bogert, N., van Bruggen, J., Kostons, D., \& Jochems, W. (2014). First steps into understanding teachers' visual perception of classroom events. Teaching and Teacher Education, 37, 208-216. https://doi. org/10.1016/j.tate.2013.09.001.

Van Es, E. A., \& Sherin, M. G. (2002). Learning to notice: scaffolding new teachers' interpretations of classroom interactions. Journal of Technology and Teacher Education, 10(4), 571-596.

Voss, J., Fincher-Kiefer, R., Green, T., \& Post, T. (1986). Individual differences in performance: the contrastive approach to knowledge. In R. Sternberg (Ed.), Advances in the psychology of human intelligence (pp. 297334). Erlbaum.

Westerman, D. A. (1991). Expert and novice teacher decision making. Journal of Teacher Education, 42(4), 292-305.

Wolff, C. E., van den Bogert, N., Jarodzka, H., \& Boshuizen, H. P. A. (2015). Keeping an eye on learning: Differences between expert and novice teachers' representations of classroom management events. Journal of Teacher Education, 66(1), 68-85. https://doi.org/10.1177/0022487114549810.

Wolff, C. E., Jarodzka, H., van den Bogert, N., \& Boshuizen, H. P. A. (2016). Teacher vision: Expert and novice teachers' perception of problematic classroom management scenes. Instructional Science. https://oi. org/10.1007/s11251-016-9367-z.

Wolff, C. E., Jarodzka, H., \& Boshuizen, H. P. A. (2017). See and tell: Differences between expert and novice teachers' interpretations of problematic classroom management events. Teaching and Teacher Education, 66, 295-308. https://doi.org/10.1016/j.tate.2017.04.015.

Zacks, J. M., Speer, N. K., Swallow, K. M., Braver, T. S., \& Reynolds, J. R. (2007). Event perception: a mindbrain perspective. Psychological Bulletin, 133(2), 273-293. https://doi.org/10.1037/0033-2909.133.2.273.

Publisher's Note Springer Nature remains neutral with regard to jurisdictional claims in published maps and institutional affiliations. 


\section{Affiliations}

Charlotte E. Wolff ${ }^{1,2} \cdot$ Halszka Jarodzka ${ }^{2,3} \cdot$ Henny P. A. Boshuizen ${ }^{2,4}$

Charlotte E. Wolff

charlottewolff@yahoo.com

1 School of Education, University of Iceland, Stakkahlið 1, 105 Reykjavik, Iceland

2 Open University of the Netherlands, Heerlen, Netherlands

3 Lund University, Lund, Sweden

4 University of Turku, Turku, Finland 